\title{
TRAJETÓRIAS E MEMÓRIAS DE NEGROS MIGRANTES
}

\author{
AlecsandroJ.P.Ratts*
}

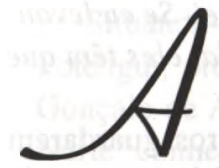

$\mathrm{s}$ migrações tornaram-se uma tradição para os moradores de agrupamentos rurais que se mantêm coesos apesar de toda a expropriação que ocorre no campo. Este artigo procura abordar essa tradição de migração entre indivíduos originários de "comunidades negras rurais" - os quilombos contemporâneos - no Estado do Ceará. Alguns desses homens e mulheres que apresentam grande mobilidade territorial participaram ativamente da formação de uma rede de agrupamentos negros baseada no parentesco e na constituição de diversas auto-imagens dentre as quais a de "uma grande família espalhada pelo país".

Sem me prender à dicotomia das abordagens da migração como mobilidade da força de trabalho ou como resultado de motivações individuais (Becker, 1997; Vainer, 1996) e indo em direção contrária às afirmações imperativas de "desenraizamento" como efeito da mobilidade extrema das famílias mais pobres (Bosi, 1987: 362), pretendo discorrer sobre um fenômeno coletivo, via histórias individuais, ressaltando a dimensão étnica: são trabalhadores, são negros e migram seguindo o percurso de outros parentes e permanecem, agregados, com algumas exceções.

Cabe indicar ainda que este artigo é fruto de uma pesquisa em andamento, e os dados apresentados se originam de narrativas basicamente orais e em alguns "objetos biográficos" (documentos cartorários, fotografias, utensílios, ruínas arquitetônicas) encontrados nas localidades em questão. $\mathrm{O}$ trabalho de campo vem acontecendo ao longo de, pelo menos, quatro anos entre os moradores de Conceição dos Caetano e Água Preta (Tururu-CE), Goiabeiras e Lagoa do Ramo (Aquiraz-
CE) e entre as famílias oriundas dessas localidades e residentes em Fortaleza. As rotas migratórias principais se dão entre os agrupamentos rurais, destes para os Estados de Amazonas, Pará e Acre e, dos agrupamentos para Fortaleza.

\section{TRAJETÓRIAS DOS ANTIGOS}

A noção de trajetória aqui utilizada não é puramente um deslocamento geométrico pois ressalta "acontecimentos biográficos" e movimentos "de uma posição a outra (de um posto profissional a outro, de uma editora a outra, de uma diocese a outra)" cujo sentido se evidencia na relação "entre sentido e valor, no momento considerado, dessas posições num espaço orientado" (Bourdieu, 1996), ou seja, são movimentações dentro de um espaço social, entre posições, mais que trajetos entre dois pontos distintos.

Os Caetano do agrupamento de Conceição costumam dizer que a "família é grande" e que está "espalhada pelo país", a partir daí listam diversos lugares onde teriam parentes: alguns são apontados como agrupamentos não mais existentes, caso de Pedregulho ou Escondido e Varjota, na região do município de Uruburetama e próximo a Conceição dos Caetano; outros marcos indicam núcleos negros atuais como os acima citados Goiabeiras, Lagoa do Ramo e Água Preta; outros lugares são referências mais genéricas como Pará, Acre, Amazonas ou ainda São Paulo e Rio de Janeiro. Tais pontos fazem parte de um território que excede às áreas atualmente ocupadas e inclui lugares de importância simbólica e política.

Os marcos temporais mais remotos se dizem respeito à Guerra do Paraguai, às secas de 1877-1879 e 1888-1889, à "libertação dos escravos" e à fundação dos agrupamentos: Conceição, 1884, Água
Preta e Goiabeiras, início do século XX. É esse o período de deslocamento dos antepassados, "os antigos". Segundo as narrativas dos mais velhos de Água Preta e Conceição, a origem de sua família se reporta à localidade de Escondido ou $\mathrm{Pe}$ dregulho, situada "a três léguas" de Água Preta, ainda na antiga região do município de Uruburetama. Nessa versão da origem, parte dos moradores de Escondido/ Pedregulho teria migrado para "o Amazonas", para arredores de Fortaleza (hoje incorporados à cidade) e para outros núcleos de negros "em Pacoti, Aquiraz, Cascavel", no norte do Estado.

"Nasci longe daqui, nasci acima de Manaus. [O meu pai] nasceu aqui. Ele sempre viajava pro Amazonas. [Foi pro Amazonas em] mil oitocentos e noventa e quatro [1894]. Chegou aqui, casouse. Nasceu aqui três filhos. Chegou os dezenove [1900], voltou pro Amazonas de novo. Nessa viagem de volta foi que eu nasci lá.

Foi só. Porque naquele tempo a rapaziada tinha interesse de ir pro Amazonas que a borracha era o meio de vida. (...)

Morou por lá uns três ano ou quatro. Teve um saldinho, desceu, veio aqui. Chegou aqui, comprou esse terreno. Casou-se, quando foi no novecentos [1900], foi seco aqui. Andamo passando fome. Da primeira vez que ele veio, ele comprou esse terreno e veio.

Quando foi novecentos [1900] foi seco. Ele entregou pro sogro dele, o Paizinho Chagas, deixou ele tomando de conta da terra e voltou. Nessa volta foi que eu nasci lá. Veio, no 1901. Veio com toda a família. A terra tinha comprado da vez que tinha vindo."

(João Bertoso, 94 anos. Água Preta, julho, 1997).

Um processo que pode ser tratado 
como mobilidade da força de trabalho para uma fronteira agrícola, assume, nas narrativas orais, o tom de uma saga familiar e inclui o mito de origem de um agrupamento. Água Preta seria uma "terra comprada" por Manuel Bertoso em sua primeira viagem para a Amazônia. A trajetória deste homem narrada por um de seus filhos se destaca das conhecidas histórias de migração de nordestinos, mais especificamente de cearenses, para os seringais amazônicos e em situação de "fuga" das grandes secas na segunda metade do século XIX e nos anos iniciais do século XX.

Manuel Bertoso foi contemporâneo de Caetano José da Costa, fundador do agrupamento de Conceição, posto que teriam residido em Escondido/Pedregulho antes da aquisição de Conceição (1884) e Água Preta (1897 ou 1898):

"Já se arretiraram tudo. Os mais velhos saíram de lá em 77 [1877], nos três oito [1888]. Saíram pro Amazonas, saíram pra Aquiraz, Messejana.

(...)

[Caetano] era desse pessoal. Depois da Princesa Isabel libertar os escravos, pois bem... Um bocado deles morava pr'ali no Pedregulho, um bocado deles morando pr'ali. Depois dessa seca que teve debandaram. Uns bocado embarcaram pro Amazonas, outros foram ali pra Messejana [Fortaleza].'

(João Bertoso, 93 anos. Água Preta, julho, 1996).

"Nos três oito [1888] já tava tudo assituado, saíram foi muitos. Embarcaram pro Amazonas. Foi muita gente, só ficou ali no Escondido o meu avô Raimundo Costa e o ti Caetano aqui da Conceição. O ti Caetano saiu pr'as Quinta e lá ganhou recurso, comprou essa terra da Conceição, levantou aquela casa, levantada toda de tijolo. O Caetano da Conceição..

As Quinta é aqui no município de Trairi. Um lagoão!"

(João Bertoso, 94 anos. Água Preta, julho de 1997).

A trajetória de Caetano indica outras rotas e processos sociais mais regionais. É citado por alguns de seus descendentes como um potencial fugitivo do recrutamento forçado de jovens solteiros para a Guerra do Paraguai, em vista do qual teria se casado com Maria Madalena da Paz.
Quando morou no Escondido/Pedregulho provavelmente era adulto e de lá teria saído à procura de trabalho na região de Uruburetama e municípios limítrofes. Ainda, segundo a tradição oral, foi morador de alguns fazendeiros.

Outros parentes teriam migrado para Fortaleza e para os agrupamentos negros de Aquiraz. Há uma outra versão dessa rota que indica o sentido contrário - de Aquiraz para Fortaleza, Uruburetama e Amazonas - mas não é possível analisá-la aqui. Contudo, coincide com a outra na afirmação do parentesco e no acento dado aos lugares de referência do grupo.

No período citado, homens pobres, "libertos", livres ou escravizados, "pretos", "mulatos" ou "pardos", segundo os termos em voga, viveram experiências semelhantes: a convivência do trabalho escravo com o trabalho livre; escapar do recrutamento forçado para a Guerra do Paraguai (Pinheiro, 1989, 1990); no caso dos escravizados, durante as grandes secas, se fazer passar por "libertos" e se esconder nos abarracamentos de "flagelados" em Fortaleza, para depois embarcar para o Amazonas, promessa de recursos e de liberdade (Oliveira, 1988); no caso de homens livres pobres, que experimentaram a condição de agregado ou morador, a associação da propriedade da terra com a liberdade (Porto Alegre, s/d).

Essa grande mobilidade tanto de libertos quanto escravizados indica ao mesmo tempo o processo de expropriação no campo - mais agudo e visível durante as grandes secas, a mobilidade da força de trabalho e a diversidade de "estratégias de sobrevivência”. É possível fazer outra abordagem.

$\mathrm{O}$ fato de que Caetano adquiriu uma gleba de terra para "viver em sossego com a sua família" sugere um projeto de autonomia e liberdade conservado por seus descendentes, representado pela "terra comum". Aparentemente aceitando as normas vigentes de acesso à propriedade fundiária após a Lei de Terras (1850), Caetano, Maria Madalena e filhos, deram continuidade a forma de viver em grupo experimentada anteriormente em Pedregulho/Escondido.

Mesmo presenciando por todo este século a migração definitiva de muitos mem- bros de sua grande família, os Caetano de Conceição preservam ser parcelar a maior parte de suas terras. A presença atual de "gente de fora" na localidade indica que os "outros", os "brancos", os "estranhos", adentraram o território negro. Há conflitos fundiários e raciais latentes cujo encaminhamento não cabe discutir aqui.

É necessário apontar que, em geral, o "tempo da escravidão" é assunto frontalmente recusado durante as entrevistas e silenciado no dia-a-dia pelos mais idosos. Seletividade compreensível para um grupo que conheceu um processo trágico (Pollack, 1989; 1992) mas cujos antepassados talvez não tenham vivido individualmente sob a condição de escravizado, como afirmam os descendentes de Caetano. Por outro lado, a experiência da escravidão, da exploração, da seca, comparece nos ideais de autonomia e liberdade que se refletem na combinação de autodefesa com contatos com o "mundo dos brancos".

Neste sentido, um dos resultados das trajetórias dos "antigos" é a constituição de novos agrupamentos e o entrelaçamento entre os moradores dos núcleos existentes para além da data da abolição formal da escravidão (1888). Como se pode verificar, um grupo de Caetanos migrou " $n a$ seca de 58" para Fortaleza e seus descendentes residem no mesmo terreno no bairro de Jardim Iracema.

\section{DESLOCAMENTOS RITUAIS}

Outro "tipo" de mobilidade consiste naquela que Max Sorre denominava de “deslocamentos rituais" (Sorre, 1994). No caso dos grupos em questão conformam os casamentos entre moradores de agrupamentos distintos, os encontros que se davam, por exemplo, nas romarias de São Francisco, em Canindé-CE, e as viagens para (re)ver parentes:

"Um tio meu [Antônio Caetano], que é ali da Conceição, um dia, foi, resolveu ir dar uma volta por lá, conhecer os parentes [da região de Aquiraz]. Depois eu fui lá [na casa dele], ele disse: 'meu filho aqui não tem negro, não. Negro tem acolá pra riba, Lá tem!'

A família é grande. Andou em todas as aldeias deles. Mas lá tem. Eu pensava 
que onde tinha mais era aqui, mas é besteira.

Às vezes situavam num canto, quando tava muito, iam uns pra frente, uns pr'um lado, uns pra outro. No Aquiraz tem uma bocadada: Aquiraz, Ramo, Coité, Pacoti. Pra acolá tudo é (?) dos negros! Quase é tudo uma parença [aparência] só." (João Bertoso, 94 anos. Água Preta, julho de 1997).

A preferência pelo casamento entre negros, levou a diversos homens e mulheres, dentre os "antigos", a contrair casamento com pessoas de outro agrupamento negro às vezes distante mais de $150 \mathrm{Km}$, como entre os núcleos de Aquiraz - Goiabeiras e Lagoa do Ramo - e Tururu - Conceição e Água Preta.

Uma trajetória individual demonstra a extensão espacial do parentesco que foi se constituindo: José Felipe da Costa, também chamado Zé Raimundo ou Zé Grande nasceu em 1903, em Goiabeiras, nas terras de seu pai. Casou com Marcelina nascida em Lagoa do Ramo, agrupamento negro vizinho. Tiveram três filhos, ela faleceu e, com eles, Zé Raimundo se dirigiu, em 1936, para Conceição, a terra dos Caetano da qual já ouvira falar. Lá, casou-se com Maria José, neta de Caetano, com quem teve seis filhos. Ela também faleceu e ele se mudou, em 1947, com uma parte dos filhos, para Capuã (Caucaia-CE), lugar de um outro agrupamento iniciado por Florêncio, filho do primeiro Caetano. Posteriormente Zé Raimundo voltou para Goiabeiras e casou, pela terceira vez, com Maria José, oriunda de Buritizal, provavelmente outro agrupamento negro, situado em Cascavel, município contíguo a Aquiraz. Zé Raimundo faleceu em 1985.

\section{MIGRAÇÃO, MEMÓRIA E ETNICIDADE}

Experimentando deslocamentos de diferentes tipos - compulsórios, voluntários, rituais - os moradores desses agrupamentos negros se constituíram como um grupo étnico cuja extensão abrange os núcleos atuais e os percursos dos antepassados reativados através de viagens, notícias e rememorações.

O dado étnico - para alguns autores de difícil identificação - é mais que "um aspecto” do fenômeno. As migrações indí- genas indicam alguns caminhos: Roberto Cardoso de Oliveira analisou os deslocamentos dos índios Terena das aldeias para as fazendas, das aldeias para as cidades e, das fazendas para as aldeias (Cardoso de Oliveira, 1968) e José de Souza Martins destacou as migrações sazonais indígenas (Martins, 1986). Considerando que alguns deslocamentos se dão em grupo, mais precisamente em família (Sader, 1988), e que a comunicação entre os migrantes e seus parentes que ficaram na área de origem pode cobrir centenas de quilômetros e duram vários anos para se consolidar (Martins, 1997), não surpreende que a dimensão étnica se sobressaia.

À primeira vista, os migrantes negros na cidade, como quaisquer outros, prescindem da memória (Santos, 1996), porém, o acompanhamento da mobilidade de indivíduos e famílias tem demonstrado que o passado intervém no presente em vestígios - fotografias, documentos cartorários, hábitos como o casamento intra-étnico e a co-residência - e em rememorações que afloram em determinados momentos e diante de interlucutores bastante precisos. Nos agrupamentos rurais indícios do passado (e, portanto, da continuidade do grupo) como fotografias, utensílios domésticos, ruínas arquitetônicas (a casa de Caetano em Conceição), parecem sugerir que são localidades plenas de memória. Mas inovações acontecem com intensidade e ritmos diferentes em cada lugar.

Os reencontros que acontecem na grande cidade, por exemplo, entre aqueles que trabalham na construção civil e provêm de distintos agrupamentos, revitalizam a visão da "grande família espalhada". A continuidade das migrações, sem abstrair sua face violenta, amplia o repertório de lugares, dos quais alguns se tornam míticos. A manutenção do vínculo com a terra de origem - "o lugar onde o umbigo está enterrado" e o empenho para conservar o que for possível dos agrupamentos rurais como "terra de trabalho", "lugares de memória", espaços tranquilos para idosos e crianças, são dimensões culturais e políticas de um processo contemporâneo.

* Alecsando J. P. Ratts é Mestre em Geografia Humana e Doutorando em Antropologia Social pela USP.

\section{BIBLIOGRAFIA}

BECKER, Olga Maria Schild

(1997) "Mobilidade Espacial da População: conceitos, tipologia, contextos". In: CASTRO, Iná Ellas; GOMES, Paulo César da Costa e CORRÊA, Roberto Lobato (Orgs), Explorações Geográficas: persursos no fim do século. Rio de Janeiro, Bertrand Brasil.

VAINER, Carlos B.

(1996) "A Violência como fator migratório: Silêncios teóricos e evidências históricas". In: TravessiaRevista do Migrante, $n^{2} 25$, maio -agosto, pp.5-9.

\section{BOSI, Ecléa}

(1987) ( $1^{\text {a }}$ ed.: 1973$)$ Memória e Sociedade: lembranças de velhos. São Paulo, T. A. Queiroz Editor/EDUSP, p. 362.

BOURDIEU, Pierre

(1996) "A llusão Biográfica". In: FERREIRA, Marieta de Morais e AMADO, Janaína (orgs.) Usos e Abusos da História Oral. Rio de Janeiro, Fundação Getúlio Vargas, pp. 183-191. (Publicado originalmente em Actes de la Recherche en Sciences Sociales $62 / 63,1986$ ).

PINHEIRO, Francisco José

(1850-1880) "O Homem Livre/Pobre e a Organização das Relações de Trabalho no Ceará". Revista de Ciências Sociais, vols. 20-21, no: 1 e 2 , Fortaleza, 1989-1990, pp. 199-230.

OLIVEIRA, Pedro Alberto de

(1988) O Declínio da Escravidão no Ceará. Dissertação de Mestrado, Recife, UFPE.

PORTO ALEGRE, Maria Sylvia

( s/d) "Fome de Braços" - Questão Nacional; Notas sobre o trabalho livre no Nordeste no século XIX. Fortaleza, Revista de Ciências Sociais, vol. 16-17, $\mathrm{n}^{\text {2* }}$ 16-17, pp. 105-142.

POLLACK, Michael

(1989) Memória, Esquecimento e Silêncio. Rio de Janeiro, Estudos Históricos, vol. 2, n² 3, pp. 3-15.

POLLACK, Michael

(1992) Memória e Identidade Social. Rio de Janeiro, Estudos Históricos, vol 5, n² 10, pp. 200212.

SORRE, Max

(1994) Migrações e Mobilidade do Ecúmeno. In: MEGALE, Januário Francisco (org.). Max Sorre, São Paulo, Ática, pp. 124-139. (Publicado originalmente em SORRE, Max, Les Migrations des Peuples, 1955).

CARDOSO DE OLIVEIRA, Roberto

(1968) Urbanização e Tribalismo: A integração do indios Terena numa sociedade de classes. Rio de Janeiro, Zahar Editores.

MARTINS, José de Souza

(1986) Não Há Terra para Plantar neste Verão: O cerco das terras indigenas e das terras de trabalho no renascimento politico do campo. Petrópolis, Vozes.

MARTINS, José de Souza

(1997) "O Tempo da Fronteira: retorno à controvérsia sobre o tempo histórico da frente de expansăo e da frente pioneira", In: MARTINS, José de Souza, Fronteira: A degradação do outro nos confins do humano. São Paulo, Hucitec.

SADER, Regina

(1988) Migração e Violência: O caso da préAmazônia Maranhense. In: São Paulo, Terra Livre, $\mathrm{n}^{\circ} 6, \mathrm{pp} .65-78$.

SANTOS, Milton

(1996) A Natureza do Espaço: Técnica e tempo, razão e emoção. São Paulo, Hucitec. 